\title{
CLINICAL
ENDOCRINOLOGY
}

\section{Differential associations of testosterone, dihydrotestosterone and estradiol with physical, metabolic and health-related factors in community-dwelling men aged 17-97 years from the Busselton Health Survey.}

\begin{tabular}{|r|l|}
\hline Journal: & Clinical Endocrinology \\
\hline Manuscript ID: & CEN-2013-000871.R2 \\
\hline Manuscript Type: & 3 Original Article - Australia, Japan, SE Asia \\
\hline Date Submitted by the Author: & n/a \\
\hline Complete List of Authors: & $\begin{array}{l}\text { Yeap, Bu; University of Western Australia, School of Medicine and } \\
\text { Pharmacology } \\
\text { Knuiman, Matthew; University of Western Australia, School of Population } \\
\text { Health } \\
\text { Divitini, Mark; University of Western Australia, School of Population Health } \\
\text { Handelsman, David; ANZAC Research Institute, University of Sydney; } \\
\text { Beilby, John; Sir Charles Gairdner Hospital, PathWest Laboratory Medicine } \\
\text { Beilin, Jonathan; Royal Perth Hospital, Endocrinology } \\
\text { McQuillan, Brendan; University of Western Australia, School of Medicine } \\
\text { and Pharmacology } \\
\text { Hung, Joseph; University of Western Australia, School of Medicine and } \\
\text { Pharmacology }\end{array}$ \\
\hline Key Words: & $\begin{array}{l}\text { Testosterone < Hormones/related: < Testis, Androgens < } \\
\text { Hormones/related: < Testis, Metabolic syndrome < Conditions: < } \\
\text { Obesity/Lipids/Nutrition }\end{array}$ \\
\hline
\end{tabular}




\section{Title}

Differential associations of testosterone, dihydrotestosterone and estradiol with physical, metabolic and health-related factors in community-dwelling men aged 17-97 years from the Busselton Health Survey.

\section{Short title}

Sex hormones in men aged 17-97 years

\section{Authors}

Bu B. Yeap ${ }^{1,2}$, Matthew W. Knuiman ${ }^{3}$, Mark L. Divitini ${ }^{3}$, David J. Handelsman ${ }^{4}$, John P. Beilby $^{5}$, Jonathan Beilin ${ }^{6}$, Brendan McQuillan ${ }^{1}$, Joseph Hung ${ }^{1}$

\section{Departments}

${ }^{1}$ School of Medicine and Pharmacology, University of Western Australia, Perth, Western Australia, ${ }^{2}$ Department of Endocrinology and Diabetes, Fremantle Hospital, Fremantle, Western Australia, ${ }^{3}$ School of Population Health, University of Western Australia, Perth, Western Australia, ${ }^{4}$ ANZAC Research Institute, Sydney, New South Wales, ${ }^{5}$ PathWest Laboratory Medicine, Sir Charles Gairdner Hospital, Perth, Western Australia, ${ }^{6}$ Department of Endocrinology and Diabetes, Royal Perth Hospital, Perth, Western Australia, Australia.

\section{Correspondence}

Bu Beng Yeap MBBS, PhD

Professor, School of Medicine and Pharmacology, Level 2, T Block, Fremantle Hospital, Alma Street, Fremantle, WA 6160, Australia. Tel: +61894313229 
Fax: +61 894312977

Email: bu.yeap@uwa.edu.au

\title{
Key words
}

Testosterone, dihydrotestosterone, estradiol, dyslipidemia, inflammation

\begin{abstract}
Acknowledgements
We thank the staff of the Busselton Health Survey and the Data Linkage Unit, Health Department of Western Australia for their assistance with the study, and the staff of PathWest Laboratory Medicine, Sir Charles Gairdner Hospital and the ANZAC Research Institute for performing biochemical and hormonal assays. We especially thank all the men who took part in the Busselton Health Survey, Western Australia.
\end{abstract}

\section{Grants and funding}

BBY is recipient of a Clinical Investigator Award from the Sylvia and Charles Viertel Charitable Foundation, New South Wales, Australia. This study was funded by the National Health and Medical Research Council of Australia (Project grant 1021326). The funding sources had no involvement in the planning, analysis and writing of the manuscript.

\section{Disclosures}

The authors declare that there is no conflict of interest that could be perceived as prejudicing the impartiality of the research reported.

Word count 3,444 


\begin{abstract}
Objectives

Lower testosterone (T) levels are associated with poorer health outcomes in older men, but associations in younger or middle-aged men are uncertain and data for dihydrotestosterone (DHT) and estradiol (E2) are limited. We assessed associations of circulating T, DHT and E2 with physical and health-related factors in a cohort comprising men aged 17-97 years.

\section{Participants and methods}

Serum from 2,143 community-dwelling men from the 1994/95 Busselton Health Survey was assayed for T, DHT and E2 using liquid chromatography-tandem mass spectrometry. Men receiving hormonal therapy, or with prostate cancer or orchidectomy were excluded.

\title{
$\underline{\text { Results }}$
}

Of the men $43 \%$ had never smoked, $6.1 \%$ had diabetes and $16.8 \%$ cardiovascular disease (CVD). Mean $( \pm \mathrm{SD})$ age was $50.3 \pm 17.0$ years. Total T was moderately correlated with DHT $(\mathrm{r}=0.56), \mathrm{E} 2(\mathrm{r}=0.35)$ and sex hormone-binding globulin $(\mathrm{r}=0.53)$. In age, smoking, body mass index (BMI) and sex hormone-binding globulin (SHBG)-adjusted analyses, T was inversely associated with metabolic syndrome score, while DHT and E2 were not associated. In multivariable models, higher total $\mathrm{T}$ was associated with lower age, BMI and C-reactive protein, and with higher creatinine and haemoglobin, independently of SHBG. Higher DHT was associated with lower age, BMI and glucose level, and higher creatinine and haemoglobin. E2 was positively associated with age, BMI and haemoglobin.

\section{$\underline{\text { Conclusions }}$}

In men spanning younger, middle and older ages, circulating androgens are more related to age and metabolic factors than CVD or chronic disease. Further investigation is required to clarify whether androgens and estrogens have contrasting roles as risk predictors for CVD. 


\section{Introduction}

As men grow older circulating levels of testosterone (T) decline [1,2]. Lower levels of $\mathrm{T}$ are associated with poorer health outcomes in older men including frailty, cardiovascular disease and mortality [3-5]. However, whether low T reflects existing ill-health or contributes to the development of disease remains unclear [5]. This debate has intensified following the report that in healthy, predominantly middle-aged men without major comorbidities, T levels might be stable and not show age-associated differences [6]. Similar T levels have also been reported when healthy young men were compared with healthy elderly men [7]. Therefore, lower $\mathrm{T}$ might reflect the presence of ill-health accumulated during ageing, representing a biomarker rather than a causal contributor to health outcomes. Alternatively, associations of lower $\mathrm{T}$ with poorer outcomes might be present in older men but attenuated in younger or middle-aged men.

In the circulation, $\mathrm{T}$ is present bound with high affinity to sex hormone-binding globulin (SHBG) and with lower affinity to albumin with a small proportion unbound or free. In large studies free $\mathrm{T}$ is commonly calculated rather than measured directly [8]. The increase in SHBG concentrations during ageing results in a greater reduction in calculated free compared to total $\mathrm{T}$ levels in older men $[7,9]$. However biological significance of calculated free $\mathrm{T}$ and its utility in the prediction of health outcomes in ageing men is debated [10]. $\mathrm{T}$ is converted by $5 \alpha$-reductase into dihydrotestosterone (DHT), a more potent ligand for the androgen receptor (AR), and by aromatase into estradiol (E2) a ligand for the estrogen receptor (ER) $\alpha$ or ER $\beta$ [11]. E2 levels have been associated with bone density in men [12]. Yet there are limited data comparing associations of T, DHT and E2 with physical, metabolic and other health-related factors in ageing men, which might clarify whether measuring levels of $\mathrm{T}$ 
metabolites provides a more comprehensive assessment of the role of male sex hormones in health and disease.

Recently liquid chromatography-tandem mass spectrometry (LC-MS) has become established as the preferred methodology for assay of sex steroids, rather than immunoassays which exhibit loss of specificity and method-dependent bias [13]. We sought to test the hypothesis that T, DHT and E2 are differentially associated with physical, metabolic and other healthrelated factors in men spanning younger, middle and older ages by measuring these sex hormones using LC-MS in a large cohort of community-dwelling men.

\section{Participants and Methods}

\section{$\underline{\text { Study population }}$}

Busselton is a coastal town in Western Australia, whose residents have participated in a series of health surveys from 1966 onwards. In 1994-1995, all surviving subjects of earlier Busselton surveys were invited to participate in a follow-up survey [14]. More than $90 \%$ of the Busselton population is of Caucasian ethnic origin. The present study is based on 2,143 men aged 17-97 years who attended the 1994/95 survey, who provided blood samples for analysis. The study was approved by the Human Research Ethics Committee of the University of Western Australia, and all participating men provided written informed consent.

\section{$\underline{\text { Assessment of medical comorbidities }}$}

Methods used in the Busselton Health Survey have been described previously [14]. Men were asked to complete a comprehensive health and lifestyle questionnaire and underwent a physical assessment. Blood pressure was measured using a mercury sphygmomanometer 
after five minutes at rest in a sitting position. Height was measured using a stadiometer and weight in light underclothes. Smoking, diabetes, and the use of antihypertensive or glucoselowering medications were obtained via questionnaire. Medical history was assessed from questionnaire responses and also via the Western Australian Data Linkage System (WADLS), which captures electronically all admissions to public or private hospitals in Western Australia [15]. A history of cardiovascular disease (CVD), including coronary heart disease or stroke, was defined as any hospital admission with a primary or secondary diagnosis of CVD during the preceding 15 years prior to the survey. History of chronic obstructive pulmonary disease (COPD) and history of chronic renal disease (CRD) were similarly defined using hospital admissions history via WADLS. Metabolic syndrome scores were defined using the NCEP ATP III 2005 definition [16]. Hypertension was defined as systolic blood pressure $\geq 130 \mathrm{mmHg}$ or diastolic blood pressure $\geq 85 \mathrm{mmHg}$ or receipt of drug treatment for hypertension. Hyperglycemia was defined as fasting glucose $\geq 5.6 \mathrm{mmol} / \mathrm{L}$. Hypertriglyceridemia was defined as triglycerides $\geq 1.7 \mathrm{mmol} / \mathrm{L}$ or receipt of fibrates or nicotinic acid. Low high density lipoprotein (HDL) cholesterol was defined as HDL $\leq 1.0$ $\mathrm{mmol} / \mathrm{L}$. Central obesity was defined as waist circumference $\geq 102 \mathrm{~cm}$. The Metabolic Syndrome score was the number of these five risk components meeting the defined criteria and a participant was regarded as having the Metabolic Syndrome if three or more criteria were met.

\section{Laboratory assays}

Blood samples were collected in the early morning after an overnight fast. Collected serum was stored at $-70^{\circ} \mathrm{C}$. Fasting serum cholesterol, $\mathrm{HDL}$ and triglycerides were determined at the time of the survey by standard enzymatic methods on a Hitachi 747 analyser (Roche Diagnostics, Australia). Glucose was measured using a hexokinase assay. Insulin was assayed 
using a Tosoh A1A-600 immunoassay analyzer using a two-site immunoenzymometric assay. The between-run coefficient of variation $(\mathrm{CV})$ was $5.6 \%$ at $14.3 \mathrm{mU} / \mathrm{L}$. We measured Creactive protein (CRP) using a particle-enhanced immunoturbidimetric assay on a Modular analyser (Roche Diagnostics, Germany). Inter-assay precision was $3.9 \%$ at $1.6 \mathrm{mg} / \mathrm{L}$ and $1.6 \%$ at $5 \mathrm{mg} / \mathrm{L}$. Plasma adiponectin levels were measured by a commercially available quantitative sandwich enzyme immunoassay technique (R\&D Systems Inc., Minneapolis, Minnesota, USA). The inter-assay coefficients of variation (CVs) ranged from 7.0 to $8.5 \%$.

Serum T, DHT and E2 were quantified within a single LC-MS run without derivatization using atmospheric pressure photo-ionisation in positive mode for androgens and negative mode for estrogens, from $200 \mu \mathrm{L}$ samples as previously described [17]. Between run imprecision for $\mathrm{T}$ was $8.6 \%$ at a concentration of $5.3 \mathrm{nmol} / \mathrm{L}$ and $7.9 \%$ at $26.9 \mathrm{nmol} / \mathrm{L}$. For DHT between run imprecision was $11.3 \%$ at a concentration of $1.3 \mathrm{nmol} / \mathrm{L}$ and $9.1 \%$ at 5.3 nmol/L. For E2 between run imprecision was $14.5 \%$ at a concentration of $73 \mathrm{pmol} / \mathrm{L}$ and $9.9 \%$ at $279 \mathrm{pmol} / \mathrm{L}$. LH was assayed using a 2 step non-competitive chemiluminometric immunoassay (Abbott Architect, Abbott Diagnostics, Australia) with between run imprecision of $5.6 \%$ at $4.8 \mathrm{IU} / \mathrm{L}$. SHBG was assayed using a solid phase, two-site enzyme immunometric assay with chemiluminescent substrate (Immulite 2000XPi, Siemens Healthcare) with between run imprecision of $3.4 \%$ at $39.4 \mathrm{nmol} / \mathrm{L}$. Free T was calculated using empirical formulae which provides closer concordance with measured free $\mathrm{T}$ compared with calculations based on equilibrium binding equations [8].

\section{$\underline{\text { Statistical analyses }}$}

Descriptive statistics are presented as mean (SD). Linear regression models were used to examine the relationships between age, body mass index (BMI) and hormone variables 
(Table 1), and the adjusted relationships between clinical and metabolic factors with hormone variables (Tables 2 and 3). Non-linearity in relationships was investigated using both the square and log transform of quantitative risk factors. To identify the important and independent correlates of each hormone variable we used a forwards stepwise selection procedure using $\mathrm{p}<0.01$ as the criterion for selection. The final fitted multivariable model from this procedure is presented (Table 4). Results from linear regression modelling are presented as the estimated difference in mean hormone level compared with reference category for categorical risk factors and for an increase of one SD in continuous risk factors together with the p-value for the association (Tables 2-4).

\section{Results}

\section{Characteristics of the study population}

There were 2,143 men who participated in the 1994/95 survey, who had provided blood samples for analysis. After excluding men reporting use of testosterone or hormonal therapy, or with a history of prostate cancer or orchidectomy $n=48$ ) and restricting the analysis to men with complete data for key variables, there were 1,920 men in this analysis. The mean $( \pm \mathrm{SD})$ age was $50.3 \pm 17.0$ years. Of these men, $43 \%$ had never smoked, $18.6 \%$ had hypertension, $3.1 \%$ were on lipid lowering therapy, $6.1 \%$ had diabetes, $2.9 \%$ had chronic pulmonary disease, $0.2 \%$ chronic renal disease and $16.8 \%$ had a history of CVD at the time of blood sampling. The age distribution of these men and the mean and SD of BMI, T, calculated free T, DHT, E2, SHBG and LH overall and for each age decade are shown in Table 1. There was an even distribution of men across decades of age except for fewer men aged 80 years and above. The overall mean for BMI was $26.5 \mathrm{~kg} / \mathrm{m}^{2}$ and was highest in $50-69$ year old men. Total and calculated free $\mathrm{T}$ levels were lower in older compared to younger men, while SHBG and LH levels were higher in older men. 


\section{TABLE 1}

\section{Associations of $T$ with DHT, E2 and SHBG}

Total T was moderately positively correlated with DHT ( $r=0.56, p<0.001)$, SHBG $(r=0.53$, $\mathrm{P}<0.001)$ and $\mathrm{E} 2(\mathrm{r}=0.35, \mathrm{p}<0.001)$ but not correlated with $\mathrm{LH}(\mathrm{r}=0.00, \mathrm{p}=0.907)$.

\section{Age-adjusted associations of hormones with smoking and obesity}

All hormone variables were significantly positively associated with current smoking after adjustment for age. Total T, calculated free T, DHT, SHBG and LH were significantly $(\mathrm{p}<0.001)$ negatively associated with BMI, waist-hip-ratio and waist circumference and the strength of the association (effect size per SD change in obesity measure) was very similar for BMI, waist-hip-ratio and waist circumference (data not shown). E2 had a significant positive relationship with BMI $(\mathrm{p}=0.004)$ and non-significant relationships with waist-hipratio $(\mathrm{p}=0.481)$ and waist circumference $(\mathrm{p}=0.203)$. Thus in further analyses all associations with clinical and metabolic variables were adjusted for age, smoking and BMI.

\section{Age, smoking and BMI-adjusted associations of hormones with clinical and metabolic factors}

After adjustment for age, smoking and BMI, total T was positively associated with HDL, haemoglobin and adiponectin, and negatively associated with lipid lowering medication, hypertension, systolic BP, glucose, insulin, triglycerides, CRP and ALT (see Table 2). Associations of calculated free $\mathrm{T}$ and DHT were similar to those found with total T, except that neither was associated with ALT, DHT was not associated with lipid lowering medication, DHT was lower in men with diabetes $(\mathrm{p}=0.012)$ and cholesterol was marginally positively associated with calculated free $\mathrm{T}(\mathrm{p}=0.021)$. Associations of SHBG were also 
similar to those found with total T except that SHBG was not associated with lipid medications and haemoglobin, and was negatively associated with diastolic as well as systolic BP and hypertension. Of note, total and calculated free T, DHT and E2 were positively associated with HDL and haemoglobin and negatively associated with insulin, triglycerides and CRP. LH was negatively associated with haemoglobin $(\mathrm{p}=0.023)$ but was not associated with any other variable. Total and calculated free T, DHT and SHBG were strongly $(\mathrm{p}<0.001)$ negatively associated with the metabolic syndrome score whereas E2 was marginally associated with metabolic syndrome $(\mathrm{p}=0.039)$.

\section{TABLE 2}

\section{Associations after additional adjustment for $S H B G$}

Several associations with total and calculated free T, DHT and E2 were attenuated after further adjustment for SHBG (Table 3). Total and calculated free T remained negatively associated with lipid medications, glucose and CRP, and positively associated with HDL and haemoglobin $(\mathrm{p}<0.05)$. DHT remained negatively associated with diabetes, glucose and CRP and positively associated with haemoglobin. E2 remained negatively associated with CRP and positively associated with haemoglobin. Alcohol consumption became more strongly associated with total and calculated free $\mathrm{T}$, and cholesterol and creatinine more strongly associated with total and calculated free T and DHT after adjustment for SHBG. After adjustment for SHBG, the metabolic syndrome score remained negatively associated with total $\mathrm{T}(\mathrm{p}=0.027)$ and calculated free $\mathrm{T}(\mathrm{p}=0.027)$ but was not associated with DHT or E2.

\section{TABLE 3}




\section{$\underline{\text { Multivariable models }}$}

The final multivariable models from the forward stepwise selection procedure are shown in Table 4. Variables in these models are necessarily significant and independent determinants of the hormone variable but the variables not selected may still be related to hormone level (see Tables 2 and 3) with their capacity already conveyed through one or more of the selected variables with which they are correlated. The significant independent determinants of SHBG were age, smoking, chronic renal disease, HDL, and adiponectin (higher SHBG) and BMI, alcohol, insulin, triglycerides, CRP, creatinine (lower SHBG). The significant independent determinants of total and calculated free T were SHBG, alcohol consumption, creatinine and haemoglobin (higher T) and age, BMI, lipid medication and CRP (lower). The independent determinants of DHT were SHBG and haemoglobin (higher DHT) and age, BMI and glucose (lower). Age, BMI, SHBG and haemoglobin were independent determinants of E2, with the difference that higher BMI was associated with higher E2.

\section{TABLE 4}

\section{Discussion}

Higher total $\mathrm{T}$ was independently associated with younger age, reduced adiposity, alcohol consumption, absence of lipid lowering medication, haemoglobin and lower CRP. There were comparable associations of DHT with several of these factors, but DHT was independently associated with lower glucose and not with alcohol or lipid medication. E2 levels were associated with age and haemoglobin, with a positive association with BMI.

Age was an independent determinant of both total and calculated free $\mathrm{T}$ levels, even allowing for SHBG. Medical comorbidities including diabetes and CVD were not independently 
associated with $\mathrm{T}$; instead metabolic risk factors reflecting central adiposity and inflammation were associated with lower levels of total or calculated free $T$. These findings are consistent with previous reports spanning younger, middle-aged and older men where total $\mathrm{T}$ declined with age in both cross-sectional and longitudinal analyses after adjustment for factors such as BMI, waist hip ratio and physical activity $[1,18,19]$. Our results contrast with the report by Sartorius et al that serum total T did not vary with age in a cross-sectional analysis of 325 men aged 40 years and above who self-reported very good or excellent health [6]. Frost et al reported similar reference intervals for $\mathrm{T}$ in healthy young and elderly men, consistent with the presence of ill-health underlying lower total $\mathrm{T}$ in elderly men [7]. In our cohort of men spanning a wider age range with co-existing medical comorbidities, increasing age was an independent determinant of lower total and free T levels, which were not lower in the presence of diabetes, pulmonary, renal or cardiovascular disease. We did not assess selfreported very good or excellent health in our study; therefore it remains possible some men without specific medical conditions might have been unwell with low levels of T. However, our results are consistent with findings in older men which support the concept that lower $\mathrm{T}$ levels in men across a span of ages are at least in part an age-associated phenomenon [20].

Our results are consistent with previous studies which identified central adiposity assessed via $\mathrm{BMI}$, waist circumference or fat mass as being closely associated with lower total $\mathrm{T}$ levels in men $[21,22]$. We found that while DHT and E2 levels appeared to be stable across decades of age, in the final multivariable model age was an independent determinant of these hormones. While age-associated changes in calculated free DHT have been reported to parallel trends seen with calculated free $\mathrm{T}$, the calculation of free DHT based on immunoassay for total DHT and SHBG has not been well validated [23]. Previously Feldman et al measured DHT by radioimmunoassay in the Massachusetts Male Ageing Study [2]. In 
that study the cross-sectional analysis of 1,709 men aged 40-70 years showed no association of DHT with age, but the longitudinal analysis found higher DHT levels in the subset of 1,156 men followed after 7-10 years. Our results contrast with previous reports of negative associations between E2 and age in cross-sectional studies using immunoassays [18,19], but are consistent with the cross-sectional analysis from the Framingham Heart Study of 1,461 men aged from 30 to $80+$ years [24]. In that study E2 was measured by LC-MS, and was positively associated with age. Therefore, when measured accurately using LC-MS, E2 is positively associated with age and BMI, and does not share the associations of $\mathrm{T}$ with metabolic factors. Longitudinal studies are required to clarify the evolution of hormone profiles with ageing.

Strengths of our study are the large size of the cohort, its inclusion of men spanning younger, middle and older ages, extensive phenotyping and availability of physical, metabolic and laboratory variables for the analyses. We assayed total T, DHT and E2 using LC-MS which provides a more accurate measurement compared to immunoassays. We explored associations of total and calculated free T, DHT and E2 with variables of interest after systematically adjusting for age, smoking, BMI and SHBG, and then using a multivariable model to identify factors independently associated with hormone levels. Thus we were able to compare distributions of T, DHT and E2 across age groups from young to old, and contrast the associations of each hormone with a range of health-related factors in a community-based cohort of men spanning young to older ages. We acknowledge several limitations of this study. This is an observational study and we performed a cross-sectional analysis thus we cannot infer causation. While WADLS possesses accuracy comparable to adjudication of medical records [25], individuals who did not require hospitalisation might not be identified by this means and reliance on data linkage remains a limitation. The men were community- 
dwelling survivors from previous surveys, thus a "healthy survivor" effect might be present making our findings more applicable to healthier older men. We used frozen serum aliquots retrieved from long term storage. Sex steroids are robust molecules with the concentrations in serum stable on assaying after 20 or more years including via LC-MS [26,27]. Even in the event of freezer failure, steroids are largely unaffected by multiple freeze-thaw cycles [28]. However, the same may not be true for proteins such as SHBG and LH. We did not have serial blood samples to assess longitudinal changes in hormones levels, instead we used a single blood sample albeit collected early in the morning to minimise the effect of circadian variation on hormone levels which may be preserved in healthy older men [29]. Additionally the Busselton cohort is almost entirely Caucasian in ethnicity thus care must be taken before extrapolating our findings to other populations.

Lower total T may be part cause and part consequence of central adiposity, and associated metabolic syndrome traits [30]. In our study T was inversely associated with metabolic syndrome score after adjusting for age, smoking, BMI and SHBG, while DHT and E2 were not associated. The contribution of DHT and E2 to cardiometabolic risk is less well understood. Suppression of DHT levels in men by administration of $5 \alpha$-reductase inhibitors such as dutasteride or finasteride does not affect bone turnover, lipid profiles or haemoglobin levels [31]. In an interventional study, the effect of exogenous $\mathrm{T}$ to increase fat-free mass in men with suppressed T production was preserved in the presence of $5 \alpha$-reductase inhibition [32]. Conversely, administration of high dose DHT to healthy men aged $>50$ years increased haemoglobin level, suppressed T, E2 and LH and decreased spinal bone mineral density most likely via the reduction in oestrogen exposure [33]. In our study, DHT shared several associations with metabolic risk factors in common with $\mathrm{T}$, but its distinct and inverse 
associations with diabetes and fasting glucose are consistent with an additive role as a biomarker for cardiometabolic risk.

Increased haematocrit can be a side effect of T or DHT therapy [33] thus the positive associations of T and DHT with haemoglobin are expected. Of note, E2 was positively associated with haemoglobin level. Further investigation would be needed to clarify whether E2 regulates haemoglobin levels in men distinct from androgens. In the final multivariable model T was inversely associated with CRP, consistent with previous studies [34]. However, DHT and E2 were not suggesting divergent associations of androgens and estrogens with inflammation. In the multivariable model, levels of T, DHT and E2 were not associated with current smoking.

Finkelstein et al reported that in men given depot goserelin acetate to suppress endogenous $\mathrm{T}$ and E2, compared to men given $\mathrm{T}$ without anastrozole, those additionally treated with the aromatase inhibitor anastrazole to fully suppress circulating E2 exhibited greater increases in subcutaneous and intraabdominal fat [35]. In our study E2 and BMI were positively correlated. Therefore, E2 may regulate as well as be regulated by adipose tissue mass. By contrast E2 does not appear to be associated with metabolic risk factors nor with the presence of metabolic syndrome in the manner of T. Thus any influence of E2 on cardiovascular risk may be limited compared to its role in other tissues such as bone [12].

In conclusion, in men spanning younger, middle and older ages circulating androgens are more related to metabolic risk factors than medical comorbidities. However, E2 does not exhibit corresponding associations with metabolic risk traits. Associations of sex hormones with age, metabolic factors and medical comorbidities may alter as men make the transition 
from middle to older age. Further investigation is required to clarify the roles of DHT and E2 distinct from $\mathrm{T}$ as a risk predictor for the development of CVD in men spanning middle to older ages.

\section{References}

1. Harman, S.M., Metter, E.J., Tobin, J.D. et al. (2001) Longitudinal effects of aging on serum total and free testosterone levels in healthy men. Journal of Clinical Endocrinology \& Metabolism, 86, 724-731.

2. Feldman, H.A., Longcope, C., Derby, C.A. et al. (2002) Age trends in the level of serum testosterone and other hormones in middle-aged men: longitudinal results from the Massachusetts Male Aging Study. Journal of Clinical Endocrinology \& Metabolism, 87, 589-598.

3. Hyde, Z., Flicker, L., Almeida, O.P. et al. (2010) Low free testosterone predicts frailty in older men. The Health in Men Study. Journal of Clinical Endocrinology \& Metabolism, 95, 3165-3172.

4. Yeap, B.B., Hyde, Z., Almeida, O.P. et al. (2009) Lower testosterone levels predict incident stroke and transient ischemic attack in older men. Journal of Clinical Endocrinology \& Metabolism, 94, 2353-2359.

5. Araujo, A.B., Dixon, J.M., Suarez, E.A. et al. (2011) Endogenous testosterone and mortality in men: a systematic review and meta-analysis. Journal of Clinical Endocrinology \& Metabolism, 96, 3007-3019.

6. Sartorius, G., Spasevska, S., Idan, A. et al. (2012) Serum testosterone, dihydrotestosterone and estradiol concentrations in older men self-reporting very good health: the healthy man study. Clinical Endocrinology, 77, 755-763. 
7. Frost, M., Wraae, K., Nielsen, T.L. et al. (2013) Similar reference intervals for total testosterone in healthy young and elderly men: results from the Odense Androgen Study. Clinical Endocrinology, 78, 743-751.

8. Ly, L.P., Sartorius, G., Hull, L. et al. (2010) Accuracy of calculated free testosterone formulae in men. Clinical Endocrinology, 73, 382-388.

9. Yeap, B.B., Almeida, O.P., Hyde, Z. et al. (2007) In men older than 70 years, total testosterone remains stable while free testosterone declines with age. The Health In Men Study. European Journal of Endocrinology, 156, 585-594.

10. Handelsman, D.J. (2007) Update in andrology. Journal of Clinical Endocrinology \& Metabolism, 92, 4505-4511.

11. Lakshman, K.M., Kaplan, B., Travison, T.G. et al. (2010) The effects of injected testosterone dose and age on the conversion of testosterone to estradiol and dihydrotestosterone in young and older men. Journal of Clinical Endocrinology \& Metabolism, 95, 3955-3964.

12. Cauley, J.A., Ewing, S.K., Taylor B.C. et al. (2010) Sex steroid hormones in older men: longitudinal associations with 4.5 year change in hip bone mineral density - the Osteoporotic Fractures in Men Study. Journal of Clinical Endocrinology \& Metabolism, 95, 4314-4323.

13. Shackleton, C. (2010) Clinical steroid mass spectrometry: A 45-year history culminating in HPLC-MS/MS becoming an essential tool for patient diagnosis. Journal of Steroid Biochemistry \& Molecular Biology, 121, 481-490.

14. Knuiman, M.W., Jamrozik, K., Welborn, T.A. et al. (1995) Age and secular trends in risk factors for cardiovascular disease in Busselton. Australian Journal of Public Health, 19, 375-382. 
15. Holman, C.D., Bass, A.J., Rosman, D.L., et al. (2008) A decade of data linkage in Western Australia: strategic design, applications and benefits of the WA data linkage system. Australian Health Review 32: 766-777.

16. Grundy, S.M., Cleeman, J.I., Daniels, S.R. et al. (2005) Diagnosis and management of the metabolic syndrome: an American Heart Association/National Heart, Lung, and Blood Institute Scientific Statement: executive summary. Circulation, 112, e285-e290.

17. Harwood, D.T. \& Handelsman, D.J. (2009) Development and validation of a sensitive liquid chromatography-tandem mass spectrometry assay to simultaneously measure androgens and estrogens in serum without derivatization. Clinica Chimica Acta, 409, 7884.

18. Ferrini, R.L. \& Barrett-Connor, E. (1998) Sex hormones and age: a cross-sectional study of testosterone and estradiol and their bioavailable fractions in community-dwelling men. American Journal of Epidemiology, 147, 750-754.

19. Rohrmann, S., Platz, E.A., Selvin, E. et al. (2011) The prevalence of low sex steroid hormone concentrations in men in the Third National Health and Nutrition Examination Survey (NHANES III). Clinical Endocrinology, 75, 232-239.

20. Yeap, B.B., Alfonso, H., Chubb, S.A.P. et al. (2012) Reference ranges and determinants of testosterone, dihydrotestosterone and estradiol levels measured using liquid chromatography-tandem mass spectrometry in a population-based cohort of older men. Journal of Clinical Endocrinology \& Metabolism, 97, 4030-4039.

21. Svartberg, J., Midtby, M., Boonaa, K.H. et al. (2003) The associations of age, lifestyle factors and chronic disease with testosterone in men: the Tromso study. European Journal of Endocrinology, 149, 145-152.

22. Firtser, S., Juonala, M., Magnussen, C.G. et al. (2012) Relation of total and free testosterone and sex hormone-binding globulin with cardiovascular risk factors in men 
aged 24-45 years. The Cardiovascular Risk in Young Finns Study. Atherosclerosis, 222, 257-262.

23. Starka, L., Pospisilova, H., Hill, M. (2009) Free testosterone and free dihydrotestosterone throughout the lifespan of men. Journal of Steroid Biochemistry and Molecular Biology, 116, $118-120$.

24. Jasuja, G.K., Travison, T.G., Davda, M. et al. (2013) Age trends in estradiol and estrone levels measured using liquid chromatography tandem mass spectrometry in communitydwelling men of the Framingham Heart Study. Journal of Gerontology: Medical Sciences, 68, 733-740.

25. Barr, E.L., Tonkin, A.M., Welborn, T.A. \& Shaw, J.E. (2009) Validity of self-reported cardiovascular disease events in comparison to medical record adjudication and a statewide hospital morbidity database: the AusDiab study. Internal Medicine Journal 39: $49-53$.

26. Holl K., Lundin E., Kaasila M., et al. (2008) Effect of long-term storage on hormone measurements in samples from pregnant women: the experience of the Finnish Maternity Cohort. Acta Oncologica, 47, 406-412.

27. Gislefoss R.E., Grimsrud T.K., Hoie K. \& Morkrid L. (2012) Stability of testosterone measured in male archival samples by two different methods. Scandinavian Journal of Clinical and Laboratory Investigation, 72, 555-562.

28. Reyna R., Traynor K.D., Hines G., et al. (2001) Repeated freezing and thawing does not generally alter assay results for several commonly studied reproductive hormones. Fertility and Sterility, 76, 823-825.

29. Diver, M.J., Imtiaz, K.E., Ahmad, A.M., Vora, J.P. \& Fraser, W.D. (2003) Diurnal rhythms of serum total, free and bioavailable testosterone and of SHBG in middle-aged men compared with those in young men. Clinical Endocrinology, 58: 710-717. 
30. Yeap, B.B., Araujo, A.B., Wittert, G.A. (2012) Do low testosterone levels contribute to ill-health during male ageing? Critical Reviews in Clinical Laboratory Sciences, 49, 168182.

31. Amory, J.K., Anawalt, B.D., Matsumoto, A.M. et al. (2008) The effect of 5a-reductase inhibition with dutasteride and finasteride on bone mineral density, serum lipoproteins, haemoglobin, prostate specific antigen and sexual function in healthy young men. Journal of Urology, 179, 2333-2338.

32. Bhasin, S., Travison, T.G., Storer T.W., et al. (2012) Effect of testosterone supplementation with and without a dual $5 \alpha$-reductase inhibitor on fat-free mass in men with suppressed testosterone production. Journal of the American Medical Association 307: 931-939.

33. Idan, A., Griffiths, K.A., Harwood, D.T. et al. (2010) Long term effects of dihydrotestosterone treatment on prostate growth in healthy, middle-aged men without prostate disease. Annals of Internal Medicine, 153, 621-632.

34. Kupelian, V., Chiu, G.R., Araujo, A.B. et al. (2010) Association of sex hormones and Creactive protein levels in men. Clinical Endocrinology, 72, 527-533.

35. Finkelstein, J.S., Lee, H., Burnett-Bowie, S-A.M. et al. (2013) Gonadal steroids and body composition, strength, and sexual function in men. New England Journal of Medicine, 369, 1011-1022. 
Table 1. Distributions of testosterone (T), calculated free testosterone (cFT), dihydrotestosterone (DHT), estradiol (E2), sex hormone binding globulin (SHBG) and luteinizing hormone (LH) stratified according to decades of age in years. Data are shown as the number (N) of men per age group and mean (SD) values for each continuous variable.

\begin{tabular}{|c|c|c|c|c|c|c|c|c|}
\hline Age (years) & $\mathrm{N}$ & BMI $\left(\mathrm{kg} / \mathrm{m}^{2}\right)$ & $\mathrm{T}(\mathrm{nmol} / \mathrm{L})$ & $\mathrm{cFT}(\mathrm{pmol} / \mathrm{L})$ & DHT (nmol/L) & E2 (pmol/L) & $\begin{array}{c}\text { SHBG } \\
(\mathrm{nmol} / \mathrm{L})\end{array}$ & LH (IU/L) \\
\hline$<30.0$ & 235 & $24.5(3.2)$ & $16.4(5.0)$ & $277(67)$ & $1.70(0.69)$ & $63.7(32.9)$ & $24.1(9.5)$ & $3.52(1.36)$ \\
\hline $30.0-39.9$ & 357 & $25.9(3.1)$ & $14.8(4.6)$ & $244(56)$ & $1.78(0.75)$ & $57.6(30.4)$ & $26.1(11.9)$ & $3.27(1.83)$ \\
\hline $40.0-49.9$ & 385 & $26.9(3.3)$ & $12.9(4.8)$ & $214(59)$ & $1.63(0.73)$ & $56.8(27.3)$ & $25.5(11.0)$ & $3.15(1.62)$ \\
\hline $50.0-59.9$ & 344 & $27.2(3.5)$ & $13.2(4.7)$ & $208(53)$ & $1.72(0.74)$ & $59.1(27.6)$ & $29.1(11.2)$ & $3.53(1.93)$ \\
\hline $60.0-69.9$ & 309 & $27.2(3.6)$ & $12.9(4.8)$ & $197(55)$ & $1.67(0.69)$ & $62.0(32.0)$ & $32.1(11.4)$ & $4.26(2.87)$ \\
\hline $70.0-79.9$ & 227 & $26.8(3.1)$ & $12.6(4.6)$ & $185(51)$ & $1.72(0.69)$ & $63.7(32.3)$ & $36.6(13.5)$ & $6.05(5.05)$ \\
\hline$\geq 80.0$ & 63 & $26.0(4.0)$ & $11.7(4.0)$ & $164(48)$ & $1.77(0.68)$ & $67.7(30.2)$ & $45.3(15.6)$ & $8.24(7.89)$ \\
\hline All & 1,920 & $26.5(3.5)$ & $13.6(4.9)$ & $218(64)$ & $1.71(0.72)$ & $60.3(30.3)$ & $29.1(12.6)$ & $3.98(3.13)$ \\
\hline $\begin{array}{l}\text { Overall p- } \\
\text { value }\end{array}$ & & $<0.001$ & $<0.001$ & $<0.001$ & 0.151 & 0.005 & $<0.001$ & $<0.001$ \\
\hline $\begin{array}{l}\mathrm{p} \text {-value for } \\
\text { trend }\end{array}$ & & $<0.001$ & $<0.001$ & $<0.001$ & 0.779 & 0.057 & $<0.001$ & $<0.001$ \\
\hline
\end{tabular}


Table 2. Age-, smoking- and BMI-adjusted* associations between each potential risk factor and testosterone (T), calculated free testosterone (cFT), dihydrotestosterone (DHT), estradiol (E2), sex hormone binding globulin (SHBG) and luteinizing hormone (LH). Table shows estimated difference in mean hormone level compared with reference category for categorical risk factors or for an increase of one standard deviation in continuous risk factors, and the pvalue for the association.

\begin{tabular}{|c|c|c|c|c|c|c|c|c|c|c|c|c|}
\hline & \multicolumn{2}{|c|}{$\mathrm{T}(\mathrm{nmol} / \mathrm{L})$} & \multicolumn{2}{|c|}{$\mathrm{cFT}(\mathrm{pmol} / \mathrm{L})$} & \multicolumn{2}{|c|}{$\mathrm{DHT}(\mathrm{nmol} / \mathrm{L})$} & \multicolumn{2}{|c|}{$\mathrm{E} 2(\mathrm{pmol} / \mathrm{L})$} & \multicolumn{2}{|c|}{$\mathrm{SHBG}(\mathrm{nmol} / \mathrm{L})$} & \multicolumn{2}{|c|}{ LH (IU/L) } \\
\hline & Est & p-value & Est & $\mathrm{p}$-value & Est & $\mathrm{p}$-value & Est & p-value & Est & $p$-value & Est & p-value \\
\hline Exercise vigorous & 0.047 & 0.839 & 2.120 & 0.461 & -0.016 & 0.658 & -2.314 & 0.151 & -0.344 & 0.544 & -0.048 & 0.752 \\
\hline Alcohol Non & 0.000 & 0.390 & 0.000 & 0.022 & 0.000 & 0.564 & 0.000 & 0.491 & 0.000 & 0.244 & 0.000 & 0.666 \\
\hline Ex & -0.719 & & -5.196 & & -0.111 & & -0.178 & & -1.332 & & 0.506 & \\
\hline Light & -0.256 & 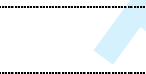 & 2.395 & & -0.121 & & -1.435 & & -2.002 & & 0.227 & \\
\hline Heavy & -0.020 & & 8.830 & & -0.116 & & 0.974 & & -2.498 & & 0.207 & \\
\hline Diabetes & -0.877 & 0.050 & -11.42 & 0.038 & -0.175 & 0.012 & 0.045 & 0.988 & -1.057 & 0.330 & -0.151 & 0.606 \\
\hline Cardiovascular disease history & 0.125 & 0.677 & 0.547 & 0.883 & 0.073 & 0.118 & -0.647 & 0.753 & -0.140 & 0.848 & -0.083 & 0.674 \\
\hline Chronic pulmonary disease history & -1.192 & 0.069 & -15.45 & 0.055 & -0.197 & 0.054 & -7.011 & 0.119 & -2.069 & 0.194 & 0.138 & 0.748 \\
\hline Chronic renal disease history & 2.271 & 0.384 & 19.92 & 0.534 & 0.060 & 0.882 & 13.40 & 0.444 & 7.991 & 0.206 & 0.101 & 0.952 \\
\hline Lipids medication & -1.480 & 0.017 & -22.02 & 0.004 & -0.139 & 0.148 & -2.520 & 0.558 & 0.384 & 0.797 & 0.476 & 0.239 \\
\hline Hypertension & -0.676 & 0.033 & -9.427 & 0.015 & -0.086 & 0.082 & 2.393 & 0.273 & -1.748 & 0.024 & -0.027 & 0.897 \\
\hline Systolic BP (SD = $15.8 \mathrm{mmHg})$ & -0.244 & 0.041 & -1.095 & 0.456 & -0.017 & 0.349 & 0.753 & 0.361 & -1.191 & $<0.001$ & -0.070 & 0.374 \\
\hline Diastolic BP $(\mathrm{SD}=10.1 \mathrm{mmHg})$ & -0.177 & 0.118 & -0.550 & 0.692 & -0.001 & 0.935 & -0.133 & 0.864 & -0.884 & 0.001 & -0.096 & 0.192 \\
\hline $\log$ Glucose $(\mathrm{SD}=0.184 \mathrm{mmol} / \mathrm{L})$ & -0.310 & 0.005 & -4.225 & 0.002 & -0.062 & $<0.001$ & -0.200 & 0.794 & -0.449 & 0.090 & -0.028 & 0.691 \\
\hline $\log$ Insulin $(\mathrm{SD}=0.603 \mu \mathrm{U} / \mathrm{mL})$ & -0.793 & $<0.001$ & -6.172 & $<0.001$ & -0.096 & $<0.001$ & -2.295 & 0.006 & -2.442 & $<0.001$ & -0.146 & 0.068 \\
\hline Cholesterol (SD = $1.04 \mathrm{mmol} / \mathrm{L})$ & 0.098 & 0.378 & 3.138 & 0.021 & 0.031 & 0.071 & -1.470 & 0.055 & -0.523 & 0.052 & 0.043 & 0.554 \\
\hline $\mathrm{HDL}(\mathrm{SD}=0.302 \mathrm{mmol} / \mathrm{L})$ & 0.828 & $<0.001$ & 6.949 & $<0.001$ & 0.083 & $<0.001$ & 2.444 & 0.001 & 2.311 & $<0.001$ & 0.059 & 0.406 \\
\hline Triglycerides $(\mathrm{SD}=1.02 \mathrm{mmol} / \mathrm{L})$ & -0.834 & $<0.001$ & -5.599 & $<0.001$ & -0.067 & $<0.001$ & -1.932 & 0.010 & -2.761 & $<0.001$ & -0.064 & 0.378 \\
\hline Metabolic score 0 & 0.000 & $<0.001$ & 0.000 & $<0.001$ & 0.000 & $<0.001$ & 0.000 & 0.039 & 0.000 & $<0.001$ & 0.000 & 0.259 \\
\hline
\end{tabular}




\begin{tabular}{|c|c|c|c|c|c|c|c|c|c|c|c|c|}
\hline 1 & -0.409 & & -3.109 & & -0.011 & & -0.415 & & -1.251 & & -0.031 & \\
\hline 2 & -1.393 & & -11.31 & & -0.162 & & -5.934 & & -3.725 & & -0.072 & \\
\hline $3+$ & -2.333 & & -22.59 & & -0.219 & & -4.115 & & -6.820 & & -0.444 & \\
\hline $\log \mathrm{CRP}(\mathrm{SD}=1.21 \mathrm{mg} / \mathrm{L})$ & -0.913 & $<0.001$ & -10.47 & $<0.001$ & -0.085 & $<0.001$ & -2.849 & $<0.001$ & -1.496 & $<0.001$ & -0.040 & 0.599 \\
\hline Creatinine $(\mathrm{SD}=17.1 \mu \mathrm{mol} / \mathrm{L})$ & -0.065 & 0.554 & 1.243 & 0.352 & 0.000 & 0.996 & -0.281 & 0.705 & -1.091 & $<0.001$ & 0.050 & 0.479 \\
\hline $\log \operatorname{ALT}(\mathrm{SD}=0.462 \mathrm{U} / \mathrm{L})$ & -0.340 & 0.004 & -2.117 & 0.140 & -0.013 & 0.482 & 0.497 & 0.537 & -0.677 & 0.017 & -0.147 & 0.055 \\
\hline Haemoglobin $(\mathrm{SD}=10.0 \mathrm{~g} / \mathrm{L})$ & 0.460 & $<0.001$ & 7.547 & $<0.001$ & 0.059 & $<0.001$ & 4.277 & $<0.001$ & -0.313 & 0.233 & -0.161 & 0.023 \\
\hline $\log$ Adiponectin $(\mathrm{SD}=0.653 \mathrm{mg} / \mathrm{L})$ & 0.531 & $<0.001$ & 3.741 & 0.005 & 0.060 & $<0.001$ & -0.832 & 0.271 & 1.847 & $<0.001$ & 0.045 & 0.525 \\
\hline
\end{tabular}

* For SHBG BMI adjustment includes BMI and BMI squared. 
Table 3. Age-, smoking-, BMI- and SHBG-adjusted associations between each potential risk factor and testosterone (T), calculated free testosterone (cFT), dihydrotestosterone (DHT) and estradiol (E2). Table shows estimated difference in mean hormone level compared with reference category for categorical risk factors or for an increase of one standard deviation in continuous risk factors, and the p-value for the association.

\begin{tabular}{|c|c|c|c|c|c|c|c|c|}
\hline & \multicolumn{2}{|c|}{$\mathrm{T}(\mathrm{nmol} / \mathrm{L})$} & \multicolumn{2}{|c|}{$\mathrm{cFT}(\mathrm{pmol} / \mathrm{L})$} & \multicolumn{2}{|c|}{ DHT (nmol/L) } & \multicolumn{2}{|c|}{$\mathrm{E} 2(\mathrm{pmol} / \mathrm{L})$} \\
\hline & Est & p-value & Est & p-value & Est & p-value & Est & p-value \\
\hline Exercise vigorous & 0.162 & 0.373 & 2.824 & 0.301 & -0.003 & 0.925 & -1.968 & 0.214 \\
\hline Alcohol & 0.000 & 0.006 & 0.000 & 0.002 & 0.000 & 0.761 & 0.000 & 0.352 \\
\hline Ex & -0.351 & 3 & -2.937 & & -0.069 & & 0.295 & \\
\hline Light & 0.318 & & 5.918 & & -0.056 & & -0.689 & \\
\hline Heavy & 0.717 & 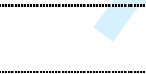 & 13.36 & & -0.032 & & 2.065 & \\
\hline Diabetes & -0.611 & 0.080 & -9.796 & 0.061 & -0.145 & 0.020 & 0.324 & 0.915 \\
\hline Cardiovascular disease history & 0.142 & 0.546 & 0.646 & 0.854 & 0.075 & 0.071 & -0.529 & 0.793 \\
\hline Chronic pulmonary disease history & -0.814 & 0.111 & -13.14 & 0.086 & -0.154 & 0.090 & -6.279 & 0.155 \\
\hline Chronic renal disease history & 0.210 & 0.918 & 7.328 & 0.810 & -0.176 & 0.626 & 9.075 & 0.597 \\
\hline Lipids medication & -1.548 & 0.001 & -22.44 & 0.002 & -0.147 & 0.085 & -2.623 & 0.534 \\
\hline Hypertension & -0.350 & 0.157 & -7.439 & 0.045 & -0.049 & 0.267 & 3.320 & 0.121 \\
\hline Systolic BP (SD = $15.8 \mathrm{mmHg})$ & 0.082 & 0.384 & 0.904 & 0.520 & 0.020 & 0.231 & 1.463 & 0.071 \\
\hline Diastolic BP $(\mathrm{SD}=10.1 \mathrm{mmHg})$ & 0.072 & 0.415 & 0.976 & 0.460 & 0.027 & 0.083 & 0.394 & 0.606 \\
\hline $\log$ Glucose $(\mathrm{SD}=0.184 \mathrm{mmol} / \mathrm{L})$ & -0.189 & 0.026 & -3.492 & 0.006 & -0.048 & 0.001 & 0.009 & 0.991 \\
\hline $\log$ Insulin $(\mathrm{SD}=0.603 \mu \mathrm{U} / \mathrm{mL})$ & -0.177 & 0.068 & -2.453 & 0.090 & -0.026 & 0.124 & -0.980 & 0.240 \\
\hline Cholesterol $(\mathrm{SD}=1.04 \mathrm{mmol} / \mathrm{L})$ & 0.256 & 0.003 & 4.114 & 0.001 & 0.049 & 0.001 & -1.158 & 0.123 \\
\hline $\mathrm{HDL}(\mathrm{SD}=0.302 \mathrm{mmol} / \mathrm{L})$ & 0.220 & 0.012 & 3.314 & 0.011 & 0.013 & 0.390 & 1.145 & 0.135 \\
\hline Triglycerides $(\mathrm{SD}=1.02 \mathrm{mmol} / \mathrm{L})$ & -0.125 & 0.160 & -1.281 & 0.335 & 0.016 & 0.306 & -0.428 & 0.574 \\
\hline Metabolic score 0 & 0.000 & 0.027 & 0.000 & 0.013 & 0.000 & 0.208 & 0.000 & 0.210 \\
\hline 1 & -0.017 & & -0.766 & & 0.034 & & 0.391 & \\
\hline
\end{tabular}




\section{Clinical Endocrinology}

\begin{tabular}{|c|c|c|c|c|c|c|c|c|}
\hline 2 & -0.444 & & -5.648 & & -0.053 & & -4.018 & \\
\hline $3+$ & -0.759 & & -13.18 & & -0.038 & & -0.768 & \\
\hline $\log \mathrm{CRP}(\mathrm{SD}=1.21 \mathrm{mg} / \mathrm{L})$ & -0.546 & $<0.001$ & -8.303 & $<0.001$ & -0.043 & 0.009 & -2.060 & 0.010 \\
\hline Creatinine $(\mathrm{SD}=17.1 \mu \mathrm{mol} / \mathrm{L})$ & 0.247 & 0.004 & 3.169 & 0.013 & 0.036 & 0.018 & 0.422 & 0.564 \\
\hline $\log \operatorname{ALT}(\mathrm{SD}=0.462 \mathrm{U} / \mathrm{L})$ & -0.149 & 0.103 & -0.946 & 0.488 & 0.009 & 0.574 & 0.902 & 0.254 \\
\hline Haemoglobin $(\mathrm{SD}=10.0 \mathrm{~g} / \mathrm{L})$ & 0.554 & $<0.001$ & 8.125 & $<0.001$ & 0.070 & $<0.001$ & 4.469 & $<0.001$ \\
\hline $\log$ Adiponectin $(\mathrm{SD}=0.653 \mathrm{mg} / \mathrm{L})$ & 0.041 & 0.632 & 0.757 & 0.558 & 0.004 & 0.777 & -1.867 & 0.013 \\
\hline
\end{tabular}

16
17

19

20

21

22
23

24

25

27

28

29
30

32

33

34
35

36

37

38
39

41

42

43

45
46

47

19 
Table 4. Final multivariable models from forward stepwise selection procedure ( $p<0.01$ for entry) with age, smoking and BMI forced into model for SHBG and and LH, and SHBG also forced into model for T, cFT, DHT and E2. Table shows estimated difference in mean hormone level compared with reference category for categorical risk factors or for an increase of one standard deviation in continuous risk factors, and the p-value for the association.

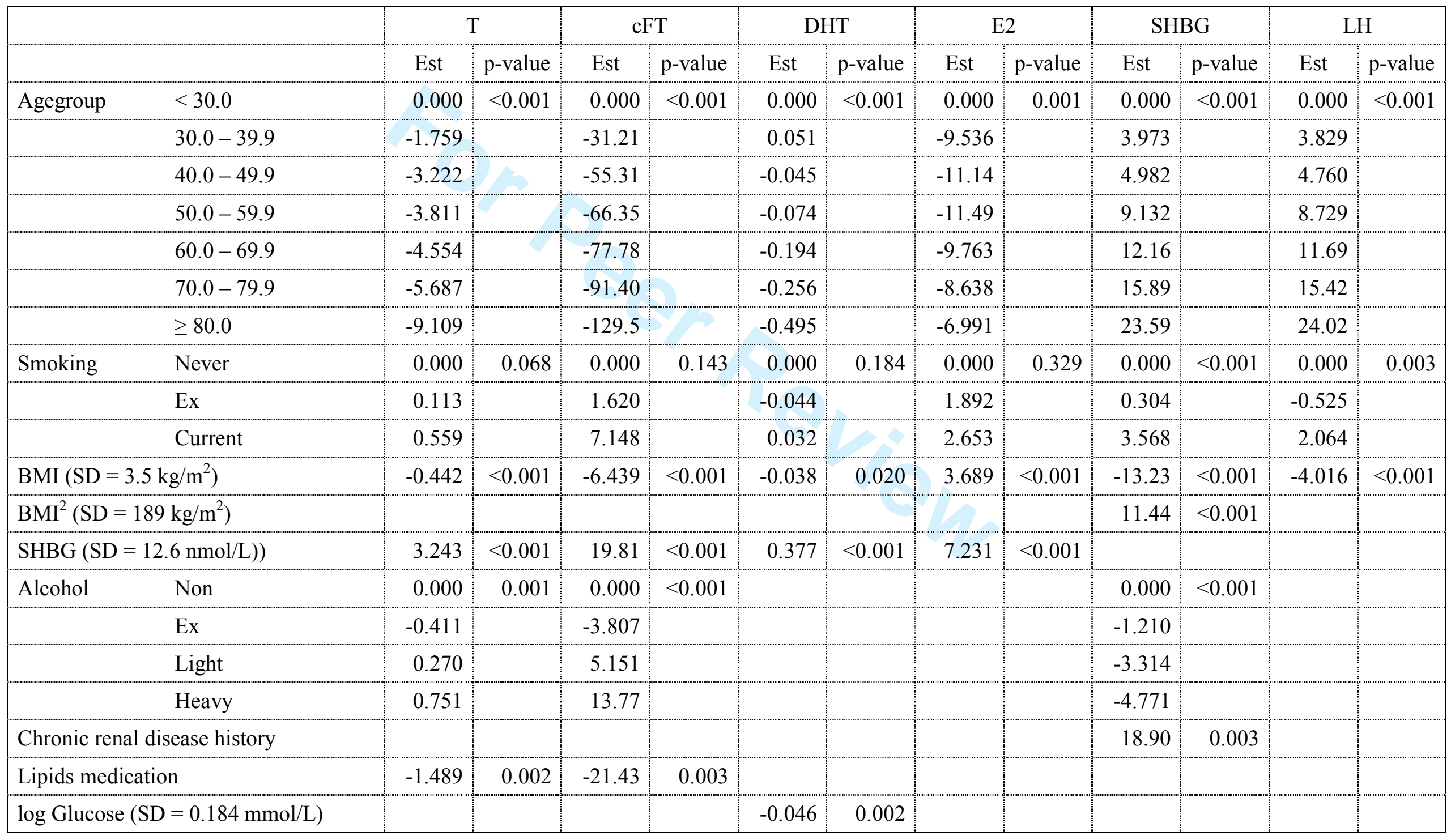




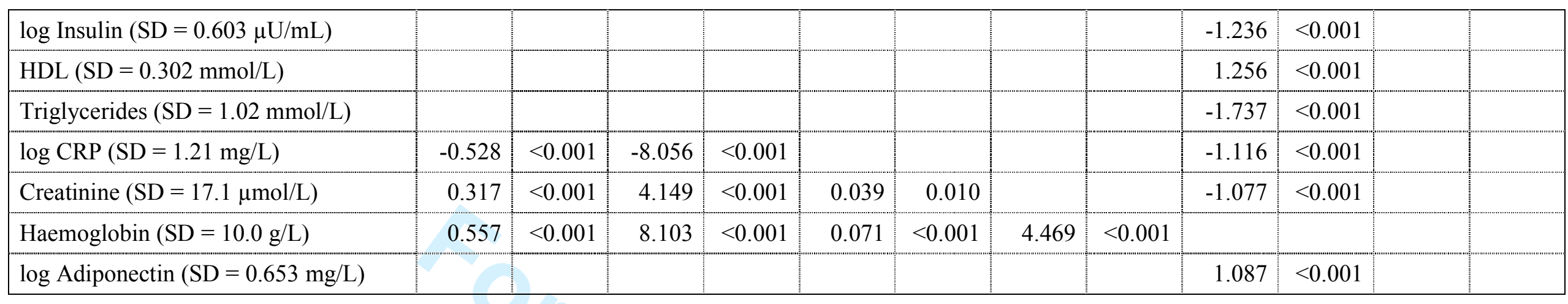

17

18
19

20

21

25

27

30

31

32

34
35

36

37

38
39

41

43

45
46

47

48 